\title{
¿Qué se esconde tras La Haya?: análisis de los discursos presidenciales y cobertura mediática en los conflictos Chile-Perú / Chile-Bolivia
}

\author{
What's hiding behind The Hague? Analysis of presidential speeches and \\ media coverage in the conflicts between Chile-Peru / Chile-Bolivia
}

\author{
María Francisca Quiroga Marambio* \\ Directora Editorial El Desconcierto, Santiago, Chile \\ Néstor Guerrero Soto ${ }^{* *}$ \\ Academia Diplomática de Chile, Santiago, Chile
}

Recibido: 15 de marzo de 2015. Aprobado: 2 de mayo de 2016.

\begin{abstract}
Resumen
Los debates públicos y análisis académicos sobre el fallo de la Corte Internacional de Justicia en el diferendo marítimo Chile-Perú, en el escenario de una nueva demanda de Bolivia, se han basado en el supuesto de pensar al Estado-nacional como categoría explicativa absoluta. La derivación lógica es que el "interés nacional” se expresaría e identificaría plenamente en el Estado-nacional. El nacionalismo es la forma simbólica ocultada, cuyos efectos enmarcan las prácticas y discursos de los actores, y se sostiene teóricamente (con intereses ideológicos) en los elementos constitutivos clásicos (y

Magíster en Ciencia Política, Universidad de Chile; licenciada en Gobierno y Gestión Pública; administrador público, Universidad de Chile; postítulo en Análisis de Discurso, Universidad de Chile. Académica Escuela Latinoamericana de Estudios de Postgrado, Universidad ARCIS. Fue directora del Magíster en Políticas Sociales y Gestión Local, de la Universidad ARCIS. Es profesora de la Academia Diplomática Andrés Bello y de la Universidad de Chile. Grupos de investigación: Ideas, discursos y política, Alacip; IPSA RC30. Comparative Public Policy. Correo electrónico: Quiroga.francisca@gmail.com

** El contenido del artículo no representa ni compromete, bajo ningún punto de vista, la visión de la Academia Diplomática de Chile o del Ministerio de Relaciones Exteriores. El autor es Magíster en Ciencia Política, Universidad de Chile; diplomado en Relaciones Chile-Perú, Instituto de Estudios Internacionales, Universidad de Chile; diplomado en Estudios Internacionales, Instituto de Estudios Internacionales, Universidad de Chile. Administrador Público y licenciado en Ciencias Políticas y Gubernamentales, Universidad de Chile. Correo electrónico: nestorguerreros@gmail.com
\end{abstract}


limitados) del Estado: población, territorio y soberanía, reafirmando la comunidad imaginada nacional. Pero se soslaya la lógica del capitalismo global y se invisibiliza la polisemia de términos como soberanía. Analizando discursos presidenciales, el artículo reflexiona acerca de ideas y discursos públicos mediatizados presentes en los conflictos Chile-Perú / Chile-Bolivia.

Palabras claves: Estado-nacional, nacionalismos, Corte Internacional de Justicia.

\begin{abstract}
Public debate and academic analysis on the sentence of the International Court of Justice regarding the maritime dispute between Chile and Peru, and in the face of a new case with Bolivia, they are based on the assumption of considering the nation state as an absolute explanatory category. The logical derivation is that the "national interest" is expressed and identifies absolutely in the nation state. Nationalism is the hidden symbolic form whose effects frame the practices and discourses of actors, and are sustained theoretically (with ideological interests) in the classics constitutive elements (and limited) of the state: population, territory, sovereignty, reaffirming the national imagined community. Nevertheless it avoids the logic of global capitalism and it conceals the polysemy of terms such as sovereignty. This article analyzes presidential discourses, reflecting on the ideas and public discourses of the conflicts between Chile-Peru and Chile-Bolivia.
\end{abstract}

Keywords: National state, Nationalisms, International Court of Justice.

\title{
Introducción: de los límites fronterizos a los límites conceptuales ${ }^{1}$
}

Estamos en un punto de inflexión en las relaciones bilaterales chileno-peruanas. Es una idea expresada con fuerza luego del fallo de la Corte Internacional de Justicia (CIJ)

Esta introducción y la siguiente sección están basadas y reproducen una parte del trabajo que uno de los autores realizó para el Proyecto Generación de Diálogo Perú-Chile / Chile-Perú, publicado en "Premio 2015 Integración y Buena Vecindad Chile-Perú / Perú-Chile”, Instituto de Estudios Internacionales (IDEI) Pontificia Universidad Católica del Perú, Konrad Adenauer Stiftung (KAS), Instituto de Estudios Internacionales (IEI) Universidad de Chile. Lima, septiembre 2015. 
el pasado 27 de enero de 2014, por el diferendo marítimo de delimitación territorial (International Court of Justice, 2014). La inflexión tendría relación con un hito histórico que permitiría, ahora sí, superar el pasado y mirar hacia el futuro. ${ }^{2}$ En efecto, pareciera existir un clima propicio para fortalecer las relaciones entre ambos países, y hubo señales inmediatas en tal sentido. A dos días del fallo, los entonces presidentes Piñera y Humala se reunieron en el marco de la Cumbre CELAC, en La Habana, y una semana después, el 6 de febrero, los ministros de Relaciones Exteriores y de Defensa de Chile y Perú se reunieron en Santiago, en la V Reunión del Comité Permanente de Consulta y Coordinación Política $(2+2)$. En otra dimensión, académicos de ambos países han realizado un trabajo colaborativo, estudiando y proponiendo medidas de políticas para aumentar los niveles de confianza mutua. Y tras la reciente elección del Presidente de Perú, Pedro Pablo Kuczynski, han existido señales políticas positivas en la dirección de retomar mecanismos diplomáticos de la relación bilateral. Sin embargo, en la misma medida en que se ha relevado una amplia agenda de colaboración y superación de desconfianzas históricas, parece haberse omitido de la panorámica general un elemento que, a decir de los especialistas, ha ejercido una influencia inmensa sobre el mundo moderno: el nacionalismo (Anderson, 1993). Tanto en la relación Chile-Perú como en la relación Chile-Bolivia, el discurso nacional parece ser un elemento central para comprender qué, realmente, se esconde tras La Haya. Por ejemplo, en el caso específico Chile-Perú, un periódico argentino explicaba el fallo de la CIJ en los siguientes términos:

Pero para muchos lo que estaba en juego en el pleito iniciado por Lima en 2008 era el orgullo nacional. Chile se apoderó de sus tres actuales provincias norteñas en la Guerra del Pacífico de 1879-83, en la cual Perú perdió territorios y Bolivia su único litoral marítimo. (La Nación, 27 de enero, 2014, énfasis propio).

El orgullo nacional, así como el nacionalismo, son conceptos derivados del término nación. En el debate público y muchos análisis académicos, sin embargo, parecen ausentes, aunque su influencia en las relaciones político-culturales de los Estadosnacionales habría que examinar. En efecto, "los últimos dos siglos de la historia humana

2 Entre otras reacciones inmediatamente posteriores a la lectura del fallo, el agente peruano Allan Wagner sostuvo que "sobre esa base debemos de continuar construyendo una relación con Chile", en: (El Comercio, 27 de enero, 2014a). La entonces Presidenta electa Michelle Bachelet expresaba el mismo ánimo, al manifestar la esperanza de que la sentencia de la Corte "marque un antes y un después, en el que seamos capaces de avanzar hacia una nueva etapa en la historia de nuestros países” (El Mercurio, 28 de enero, 2014). El alcalde de Tacna, Fidel Carita, señaló que "la ganancia para el pueblo tacneño era la paz y la tranquilidad" y que ahora "debemos preocuparnos por la integración” (El Comercio, 27 de enero, 2014b). El líder de la Asociación de Exportadores (ADEX). Eduardo Amorrortu señaló que el fallo "acabó con un elemento de desconfianza que distraía a los gobiernos y que ahora permitirá que las fronteras se mantengan abiertas” (Perú 21, 28 de enero, 2014). 
del planeta Tierra son incomprensibles si no se entiende un poco el término 'nación' (Hobsbawm, 1991, p. 9), y no se entiende, asimismo, si no se indaga por qué la nacionalidad tiene una legitimidad emocional tan profunda (Anderson, 1993).

No obstante, la estrategia chilena no habría considerado elementos en esencia políticos, centrándose excesivamente en la función técnico-procesal del derecho internacional, lo que fue constatado y criticado por analistas simbólicos (Rodríguez, 2014). En el escenario de la demanda del Estado Plurinacional de Bolivia al Estado de Chile ante la CIJ y una nueva demanda, esta vez de Chile, ante el mismo organismo, ese aspecto ha buscado subsanarse mediante estrategias políticas, comunicacionales y diplomáticas. Por cierto no existen aún elementos suficientes para evaluar los resultados de ese giro táctico. Más allá de ese factor, el elemento político-cultural que el nacionalismo implica para las relaciones vecinales no forma parte del mapa de aristas en el análisis del fenómeno.

En ese marco, el objetivo del presente artículo es reflexionar acerca de las ideas predominantes y los discursos hegemónicos que se expresan en la discusión pública sobre los casos Chile-Perú / Chile-Bolivia, en el marco de las demandas ante la Corte Internacional de Justicia de La Haya. Para ello, aparte de esta introducción, el trabajo contiene cuatro secciones. La primera aborda los supuestos ideológicos del discurso sobre el Estado-nacional, ahondando en el nacionalismo como forma simbólica y en el análisis de los elementos clásicos del Estado-nacional, reforzados por tal construcción discursiva. La segunda sección detalla el procedimiento metodológico y exhibe brevemente la propuesta de análisis crítico del discurso. Las secciones tercera y cuarta abordan en profundidad ambos casos de estudio, incluyendo análisis de posiciones de actores oficiales, lógicas mediáticas y conceptos recurrentes mediante mapas ramificados de prensa. Se finaliza el texto con las conclusiones.

\section{El discurso del Estado-nacional}

John Thompson, en Ideología y cultura moderna. Teoría crítica social en la era de la comunicación de masas (2002), moviliza la categoría central de 'formas simbólicas' para referir "una amplia gama de acciones y lenguajes, imágenes y textos, que son producidas por los sujetos y reconocidos por ellos y por otros como constructos significativos" (2002, p. 89). Utilizando funcionalmente dicha categoría, es factible pensar el nacionalismo como una forma simbólica en tanto se expresa en discursos, es performativa y puede configurar relaciones del tipo nosotros/ellos, significando 
realidades concretas. En ese sentido, dado que se habla poco o nada del nacionalismo y que parece ser una realidad sempiterna, bien puede considerársele como una ideología, es decir, como parte de aquellos "conjuntos unificadores orientados a la acción, racionalizadores, legitimadores, universalizadores y naturalizadores" (Eagleton, 1997, p. 71). Pues no puede considerarse la nación, y por consiguiente el nacionalismo, como un fenómeno universal e invariable. La nación, en efecto, "pertenece exclusivamente a un período concreto y reciente desde el punto de vista histórico. Es una entidad social sólo en la medida en que se refiere a cierta clase de estado territorial moderno, el 'estado-nación' (Hobsbawm, 1991, p. 18).

Chile, Perú y Bolivia son, así vistos, Estados-nacionales modernos, estructuras sociopolíticas recientes. La nación, en tanto, es un constructo artificial, cultural. No precede a la historia, no es natural, no es primaria ni permanente. Y dado que el nacionalismo podría ser pensado como una forma simbólica cuya matriz es ideológica, es factible sostener que la creación cultural que supone es estratégica, es decir, tiene unos fines determinados que, en el campo de la ideología, muy posiblemente, han sido ocultados.

Nación, nacionalidad y nacionalismo son "artefactos culturales de una clase particular" (Anderson, 1993, p. 21), productos de una "ingeniería social que interviene en la construcción de naciones” (Hobsbawm, 1991, p. 18).

Sin embargo, puede sostenerse con total razón que el Estado-nación ha sido puesto en jaque por las lógicas de la globalización. Sus elementos constitutivos clásicos han sido cuestionados. Y a ello parece haber contribuido decididamente la configuración del orden mundial. Bauman (2006) y Castells (1999) sostienen tesis en este sentido. No obstante, los análisis históricos en el campo internacional sugieren lo contrario. Tras el término de la Guerra Fría, "el fin de la era del nacionalismo, anunciado durante tanto tiempo, no se encuentra ni remotamente a la vista. En efecto, la nacionalidad es el valor más universalmente legítimo en la vida política de nuestro tiempo" (Anderson, 1993, p. 19).

La historia político-cultural de la relación Chile-Perú y Chile-Bolivia demuestra la fuerza del nacionalismo como un principio de unidad política y nacional (Hobsbawm, 1991) que, por tanto, configura relaciones del tipo nosotros/ellos. Se "impone a todas las demás obligaciones públicas, y en los casos extremos (tales como las guerras) a todas las otras obligaciones, del tipo que sean" (Hobsbawm, 1991, p. 17). Es reforzado permanentemente a través de símbolos, discursos y prácticas, tales como las banderas, las fronteras, los himnos nacionales, los héroes, los mitos, los mapas, los museos, entre otros. En su conjunto, hacen 
realidad una ficción, una entelequia. Un ejemplo recurrente, considerando la coexistencia de escolares chilenos y peruanos en colegios chilenos, ha sido que al iniciar sus jornadas se entonan ambos himnos nacionales, y ello reflejaría una señal de integración. A decir verdad, el efecto performativo del ritual es el reforzamiento de la "conciencia nacional" de cada país, ahora compartida y con condiciones de posibilidad de expresión pública en el aparato ideológico estatal por excelencia: la escuela. La conciencia nacional tiene directa relación con el modo de concebirnos como formando parte de una comunidad, distinta de "otras" comunidades. No es importante conocer, de hecho, a cada integrante de la comunidad de la cual formamos parte "nosotros"; lo que importa es reconocer que somos una entidad unida, delimitada territorialmente y unificada culturalmente.

Es la definición propuesta por Benedict Anderson (1993) para nación: una comunidad política imaginada como inherentemente limitada y soberana. Como se indicó, es imaginada,

porque aun los miembros de la nación más pequeña no conocerán jamás a la mayoría de sus compatriotas, no los verán ni oirán siquiera hablar de ellos, pero en la mente de cada uno vive la imagen de su comunión (p. 23).

El día de la lectura del fallo de la CIJ en el caso Chile-Perú, esa solidaridad nacional fue evidente en las reacciones de apoyo que hubo hacia los habitantes y pescadores ariqueños, que resintieron las consecuencias de la sentencia (Woo, 2014). Pudiera ser contradictorio, empero, que mientras se solidariza con quienes resguardan la frontera en tanto la habitan cotidianamente, la construcción de la nación los haya, desde su punto de vista, olvidado, bien porque la nación se ha construido de arriba hacia abajo, o bien, desde el centro hacia la periferia, en una lógica centralista (Galdames, 2010).

La nación, asimismo "se imagina limitada". Que las fronteras estén claramente delimitadas es un factor crucial para limitar la ficción. Por ello, la disputa territorial Perú versus Chile en la CIJ, y la demanda de Bolivia contra Chile, afectan el core de la comunidad imaginada nacional. En términos de política exterior en la era contemporánea el leitmotiv ha sido sustentar y defender

el principio de la soberanía plena e incuestionada de cada uno sobre su territorio, de borrar los escasos 'puntos en blanco' que quedaban en el mapa y rechazar el peligro de ambivalencia derivado de algunas superposiciones de soberanía o reclamos territoriales no resueltos. (Bauman, 2006, p. 84).

\section{Si Somos Americanos. Revista de Estudios Transfronterizos}


Los mapas, en ese marco, devienen símbolos que cristalizan la limitación. Fijan una gramática y moldean profundamente el dominio territorial del Estado (Anderson, 1993). Los mapas expresan y constituyen las fronteras internacionales.

Situadas en los límites entre los territorios estatales adyacentes, las fronteras internacionales tienen una significación especial para determinar los límites de la autoridad soberana y definir la forma espacial de las regiones políticas contenidas (...) fronteras (...) aparecen donde las entrecaras verticales que hay entre las soberanías estatales intersecan la superficie de la tierra (...). Como entrecaras verticales, los límites no tienen extensión horizontal. (Muir, 1975, p.119; citado en Anderson, 1993, p. 240).

La comunidad por cierto también se imagina soberana. Por último, se imagina comunidad

porque, independientemente de la desigualdad y la explotación que en efecto puedan prevalecer en cada caso, la nación se concibe siempre como un compañerismo profundo, horizontal. En última instancia, es esta fraternidad la que ha permitido, durante los últimos dos siglos, que tantos millones de personas maten y, sobre todo, estén dispuestos a morir por imaginaciones tan limitadas. (Anderson, 1993, p. 23).

Pero la moderna nación tiene un acompañante que la dota de sentido, excluye otras formas simbólicas posibles y la determina políticamente: el Estado. Al consultar la definición de Estado en los textos de Derecho Internacional Público, se postula en general que para afirmar su existencia se requieren cuatro condiciones: debe existir un pueblo; debe existir un territorio en el que se establezca ese pueblo; debe existir un gobierno; y ese gobierno debe ser soberano (Oppenheim, 1961; énfasis propio). Esta noción jurídica se asimila al concepto weberiano de Estado, es decir, "aquella comunidad humana que, dentro de un determinado territorio (el 'territorio' es elemento distintivo), reclama (con éxito) para sí el monopolio de la violencia física legítima”. (Weber, 1979, p. 83).

El Estado-nacional, en esta perspectiva, ancla su existencia y permanencia al derecho internacional. En efecto, es parte de las críticas realizadas a la estrategia jurídica de Chile. Y esa tendencia jurídico-formal habría sido correctamente leída por la diplomacia peruana (y por la boliviana), llevando a Chile a su campo predilecto: un tribunal de justicia internacional. La estrategia jurídica, cabe decirlo, tendría como uno de sus fundamentos la estabilidad del régimen internacional de los territorios (van Klaveren, 2011). El territorio y sus fronteras nacionales, cristalizadas en mapas, es un valor central de la comunidad internacional. La globalización, señala van Klaveren, "no ha alterado 
el carácter casi sagrado que la población de los países asigna al territorio en que vive o, más exactamente, que le pertenece (2011, p. 154). Pero la lógica y velocidad de los movimientos globales, máxime el capital económico, arguye Bauman (2006), se desplaza con tal rapidez que mantiene siempre "un paso de ventaja" sobre cualquier gobierno territorial.

Pero las fronteras resisten y allí sus poblaciones materializan la construcción de un "otro" tras los límites para afirma la propia identidad. El historiador Sergio González ha visto cómo

el carácter fronterizo de Tarapacá marcó también el carácter de la sociedad, que siempre estuvo consciente estar viviendo en una zona limítrofe, donde la "otredad" fue un imperativo, en el sentido que allí no cabía sino definirse por oposición. Entonces, la representación territorial fundamento de la identidad nacional, fue al mismo tiempo proceso de construcción del otro, un othering. (2010, p. 1).

Se presenta así una aparente paradoja: las poblaciones nacionales veneran sus territorios delimitados y afirman allí su identidad, pero la entidad responsable del territorio (el Estado-nacional) es sobrepasada por lógicas supranacionales, por movimientos transfronterizos y por cuestionamientos a la soberanía estatal.

Esa contradicción abre otro campo de análisis, el de la soberanía. Hace un tiempo atrás, el otrora ministro de Defensa Nacional de Chile, Jorge Burgos, fue categórico en señalar que "los chilenos siempre seremos inflexibles en defender la soberanía" (El Mostrador, 11 de agosto, 2014). Conforme el análisis de la estructura argumentativa del uso del concepto soberanía en la política exterior chilena, ésta siempre se identifica plenamente con el territorio físico delimitado, pertenece legítimamente a un "nosotros" (la comunidad imaginada nacional) y se defiende jurídicamente con el derecho internacional. Los discursos presidenciales en Chile, en el marco de las demandas territoriales tanto de Perú como Bolivia, así lo evidencian.

Hay, por lo tanto, un continuo refuerzo de la soberanía en tales términos, invisibilizando significados alternativos disponibles. El refuerzo se explica por la amenaza a que ha sido sometida la soberanía, tal como la pensaron los clásicos. Nuevamente, el derecho internacional dispone de un repertorio defensivo, pues desde su punto de vista "no tiene sentido hablar del fin de la soberanía" (Hillgruber, 2009, p. 12), ya que "de la imposibilidad práctica de una actuación soberana no se deriva lógicamente la inexistencia de soberanía, pues, como concepto jurídico que es no desea saber cómo es la práctica estatal, sino

\section{Si Somos Americanos. Revista de Estudios Transfronterizos}


cómo debe ser ésta en caso de conflicto" (Di Fabio, 1998 citado en Hillgruber 2009). Así vista, la soberanía se activa y los actores políticos apelan a la soberanía cuando se presentan coyunturas críticas (crisis o conflictos), no durante las coyunturas rutinarias; de lo que se deduce su interpelación oportuna en el marco de las demandas cruzadas entre los países vecinos ante la CIJ.

Junto al territorio y la soberanía, la población se prescribe como otra condición necesaria para afirmar la existencia del Estado. Pero ya no es factible pensar las poblaciones nacionales sin considerar el fenómeno migratorio y su efecto social, el multiculturalismo. $\mathrm{Si}$, como dice Sartori, el Estado-nacional es cada vez menos una unidad de análisis significativa y los sistemas sociales se hacen cada vez más trasnacionales, entonces se asiste "a lo que Bell denomina la pérdida del espacio aislante" (Sartori, 2000, p. 323). Ello

libera" al hombre nuevo de su pasado, de sus raíces culturales y de cualquier apego preexistente, para bien y para mal. En este sentido, los hombres con seguridad, están "convergiendo"; es decir, haciéndose más monótonos, más parecidos, a través de las fronteras nacionales... La convergencia de la que hablo no crea amistad ni acercamiento político entre los pueblos, así como no cancela -aunque las pueda modificar- las áreas de hostilidad y de afinidades ideológicas. (Sartori, 2000, p. 324).

En el caso chileno, habría que aportar evidencia para desmitificar algunos discursos que circulan sobre la dinámica migratoria. Respecto de la inmigración peruana, "como otros países vecinos, es parte de un proceso social de escala ampliada, que tiene historia y no parece mostrar vestigios de cambio" (Martínez, 2005, p. 144). La evidencia censal da cuenta de que, además, "los inmigrantes tienen calificaciones superiores a las de la población chilena, particularmente en el caso de los peruanos, cuya inmigración es esencialmente de carácter laboral" (Martínez, 2005, p. 145). En cualquier caso, los análisis estadísticos basados en la comparación de los últimos dos censos "no calzan con los argumentos de 'oleadas' o 'invasiones' de inmigrantes" (Martínez, 2005, p. 145). Y, finalmente, en los debates sobre las migraciones no debe olvidarse la relevante emigración chilena hacia otros países.

Entonces, cabe agregar la siguiente interrogante: “itenía el estado-nación una función específica como tal en el proceso de desarrollo capitalista?" (Hobsbawm, 1991, p. 34). La pregunta, de carácter retórico, ilumina tal vez parte de la interrogante sobre el papel de ocultamiento que la forma simbólica nacionalismo, en tanto ideología, supone. La economía capitalista, y hoy la estructura económica internacional, lo demuestra y parece un inmigrante ilegal que, cada vez más y con mayor rapidez, vulnera las fronteras 
nacionales. "El límite era, no podía por menos de serlo, el mercado mundial” (Hobsbawm, 1991, p. 35). Aún más, "la autodeterminación para las naciones sólo era aplicable a las naciones que se consideraban viables: cultural y, desde luego, económicamente" (Hobsbawm, 1991, p. 41). Cabría realizar un análisis profundo y específico sobre las consideraciones económicas que influyen en los conflictos vecinales.

Teniendo en cuenta los elementos reseñados, las siguientes secciones analizan los discursos públicos mediatizados que se pueden advertir en los escenarios de las demandas que Perú y Bolivia, en momentos distintos pero continuos, han establecido contra Chile en la Corte Internacional de Justicia.

\section{Encuadre metodológico y categorías analíticas}

Este trabajo recurre al estudio de caso como estrategia de investigación. Considerando las premisas teóricas asumidas, la búsqueda de interpretaciones a partir de interrogantes cualitativas, la imposibilidad de controlar los acontecimientos estudiados y la contemporaneidad de los investigadores con los hechos investigados, esta metodología resulta ser la más pertinente (Yin, 2009). Sobre esa base, el corpus de análisis está conformado por discursos públicos presidenciales representativos en Chile y Perú, y de medios de comunicación en Chile en torno a las demandas Perú vs Chile y Bolivia vs Chile ante la Corte Internacional de Justicia. Para estudiar dicho corpus se ha recurrido a categorías provistas por el análisis crítico del discurso (ACD), que asume el discurso como "un complejo conjunto de actos lingüísticos simultáneos secuencialmente interrelacionados (...) que se manifiestan a lo largo y ancho de los ámbitos sociales de acción como muestras semióticas (orales o escritas y temáticamente interrelacionadas) y muy frecuentemente como textos" (Wodak y Meyer, 2003, p. 170). En tanto textos, se inscriben en un contexto determinado y, en ese sentido, es posible identificar en ellos subtextos. Para Teun Van Dijk (2005b), el discurso es un acontecimiento comunicativo en una situación social, cuyos actores participantes y sus roles determinan acciones (Van Dijk, 2005a). El discurso, así visto, además de un corpus de análisis, puede ser utilizado para transformar acontecimientos sociales (Pardo, 2007; White, 2013).

Producto de investigaciones empíricas realizadas bajo el enfoque del ACD, este trabajo utiliza algunas categorías de análisis o "estrategias discursivas" contenidas en los discursos (Van Dijk, 2005; Pilleux, 2001, las cuales luego, en vinculación con la teoría, permiten ensayar una interpretación crítica. Las estrategias discursivas son aquellas 
representaciones cognitivas de una secuencia de acciones a ser ejecutadas (Van Dijk, 2005, es decir, connota los diferentes recursos lingüísticos a los que acude el emisor para administrar el habla, es decir, para adquirirlo, comprenderlo y reproducirlo en formatos textuales. La finalidad de la identificación de estrategias discursivas en un discurso es evaluar, de manera eficaz, el significado, las funciones lingüísticas, interaccionales, sociales, pragmáticas y psicológicas de los enunciados en el discurso. La comprensión y la producción de los enunciados están estrechamente relacionados con estas estrategias (Pilleux, 2001).

Van Dijk (2005) distingue tres agrupamientos de estrategias discursivas: semánticas, sintácticas y retóricas. Las estrategias semánticas establecen lo que significa y de qué se trata el discurso, operando como expresión de las macroestructuras y los modelos cognitivos de situación (Van Dijk, 2005). Es similar a la idea de marcos cognitivos o framework, en un nivel lingüístico. Las estrategias sintácticas se relacionan con la coordinación y asociación estratégica de las palabras. El análisis sintáctico permite identificar los tipos de relación entre las formas gramaticales para detectar funciones de ideología a través del uso del lenguaje (Pelayo y Cabrera, 2001). Finalmente, las estrategias retóricas cumplen el papel de persuasión a través de diversas figuras discursivas que deben parecer razonables y aceptables. El cuadro exhibe los principales tipos de estrategias discursivas de cada uno de los agrupamientos. 
Cuadro $\mathrm{N}^{\circ} 1$

Principales tipos de estrategias discursivas según agrupamiento

\begin{tabular}{|c|c|}
\hline Semánticas & Retóricas \\
\hline $\begin{array}{l}\text { Uso de pronombres inclusivos o Relación causa-efecto, } \\
\text { excluyentes, que marcan el eje de cuya función es vincu- } \\
\text { distancia o cercanía que tiene el lar de modo interesado } \\
\text { productor del discurso con la reali- dos o más hechos. } \\
\text { dad referida, determinando un en- Orden de las palabras, } \\
\text { dogrupo o un exogrupo. Fija la re- cuya función es jerar- } \\
\text { lación "nosotros" versus los "otros". quizar un conjunto de } \\
\text { Frase nominal dotada de poder elementos mediante la } \\
\text { identificatorio, es decir, frases con priorización de unos en } \\
\text { sentido ampliamente reconocidas y perjuicio de otros. } \\
\text { reproducidas por los actores en un } \\
\text { contexto sociopolítico. } \\
\text { Uso de contrastes, es decir expre- } \\
\text { siones que se basan en los antó- } \\
\text { nimos para realzar el mensaje del } \\
\text { discurso. } \\
\text { Uso estratégico del léxico, es decir, } \\
\text { la elección estratégica que se hace } \\
\text { de las palabras para darle mayor im- } \\
\text { pacto al mensaje del discurso. } \\
\text { Uso de transferencias, mediante la } \\
\text { delegación de la responsabilidad de } \\
\text { actos o frases a otros actores del es- } \\
\text { cenario sociopolítico. } \\
\text { Uso de mitigadores, cuya función } \\
\text { es moderar la intensidad del discur- } \\
\text { so con diversos fines. }\end{array}$ & $\begin{array}{l}\text { Ritual de recordación, que } \\
\text { se utiliza para evocar una } \\
\text { situación o hecho histórico } \\
\text { que tiene significado en un } \\
\text { contexto sociopolítico de- } \\
\text { terminado. } \\
\text { Uso de palabras de sinceri- } \\
\text { dad, es decir, palabras con } \\
\text { alto contenido emocional } \\
\text { y que, por tanto, operan } \\
\text { como complemento per- } \\
\text { suasivo de los argumentos } \\
\text { lógicos. } \\
\text { Uso de figuras arquetípi- } \\
\text { cas, es decir, la alusión a } \\
\text { figuras emblemáticas que } \\
\text { son representativas en el } \\
\text { imaginario colectivo. } \\
\text { Uso de la pregunta, que ge- } \\
\text { neralmente adopta la forma } \\
\text { de pregunta retórica, inter- } \\
\text { pelando a los receptores se- } \\
\text { gún el cuadrado ideológico } \\
\text { del hablante. }\end{array}$ \\
\hline
\end{tabular}

Fuente: adaptado de Quiroga (2007), sobre la base de Manual de Análisis de Discurso y Manejo de Crisis Comunicacionales.

Adicionalmente, el ACD provee otros valiosos recursos analíticos para el estudio de discursos públicos. Mencionaremos aquí las implicaturas, las presuposiciones y los actos de habla. Las implicaturas son las indicaciones implícitas o tácitas, una inferencia del texto o discurso. Es llamado también contenido latente, desde la óptica del análisis de contenido. Las presuposiciones son los conocimientos compartidos que el productor de 
discurso sabe que tiene con el grupo objetivo y que permite la interacción con sentido (Quiroga, 2007, pp. 11-15). Los actos de habla son acciones lingüísticas que tienen efectos performativos sobre la realidad; en términos sencillos es el "lenguaje en acción": crítica, amenaza, interpelación, promesa. Los actos de habla son parte de un lenguaje "performativo" más que "constatativo", es decir, no sólo se consideran los elementos fácticos-descriptivos, sino que la puesta en escena de los discursos y sus efectos en la realidad (Austin, 1955).

Estas categorías de análisis son movilizadas para estudiar los discursos públicos en torno a los casos de las demandas de Perú y Bolivia vs Chile ante la Corte Internacional de Justicia, particularmente en un eje temporal específico comprendido entre el momento en que se dicta el fallo del caso Perú vs Chile y el momento antes de que se interponga el recurso de Bolivia. Las fuentes de información a las que se recurrió fueron dos. En primer lugar, se seleccionaron piezas que ilustran énfasis de los discursos presidenciales en Chile, Perú y Bolivia en torno a los casos analizados. En particular se consultaron discursos y declaraciones de autoridades políticas. En segundo lugar, con el objetivo de complementar los análisis previos y observar el modo de reproducción en los medios de comunicación escritos chilenos, se registraron y sistematizaron 200 titulares publicados por cuatro periódicos en torno al caso Chile vs Perú: La Tercera, El Mercurio, El Mostrador y La Segunda, desde el 27 de enero al 30 de agosto de 2014. Tal información se procesó con el programa de análisis cualitativo de datos Nvivo, generándose un mapa ramificado que expresa la frecuencia de palabras seleccionadas. Bajo el mismo procedimiento, para el caso Chile vs Bolivia, se registraron y sistematizaron 107 titulares publicados por cuatro periódicos chilenos: La Tercera, El Mercurio, El Mostrador y La Segunda, desde el 27 de enero al 30 de agosto 2014, generándose un mapa ramificado que expresa la frecuencia de palabras sobre el tópico de la demanda de Bolivia ante la Corte Internacional de Justicia.

\section{El caso Chile-Perú}

Hay diferentes estudios sobre las relaciones bilaterales de Chile y Perú. En particular se abordan las interacciones en el contexto político, social, histórico, cultural y económico con una mirada a los procesos del siglo XX, mencionando como un hito clave la Guerra del Pacífico, un marco contextual en donde "los discursos de la vieja Guerra del Pacífico han tenido gran injerencia en las conformaciones identitarias nacionales entre ambos países, evidenciándose notoriamente las mutuas desconfianzas históricas" (Browne y Yáñez, 2012, p. 190) y los procesos de desarrollo que han vivido ambos países. Se destacan 
en general, como variable fundamental para los procesos de integración, la dimensión económica basada en relaciones comerciales de carácter instrumental, surgiendo en la década de 1990 y 2000 iniciativas de cooperación e investigación que exaltan la relación comercial y el aumento de las inversiones. Al respecto, se evidencia una valoración de la

profundización de la relación comercial y de inversión entre Chile y Perú que se ha gestado durante los últimos años [que] es un activo que debe ser explotado por los gobiernos de ambos países para la construcción de programas y políticas que puedan aportar al desarrollo y acercamiento de ambos países. (López y Muñoz, 2011, p. 16).

En esta misma línea, y en línea con lala hipótesis de la viabilidad económica, hay autores que afirman que

a partir de 1990, y hasta el año 2010, el intercambio comercial entre Chile y Perú creció a un ritmo anual promedio del $16 \%$. Es de especial interés analizar el dinamismo de los flujos bilaterales de comercio a partir de la entrada en vigencia del Acuerdo de Cooperación Económico (AC) 38 en 1998. (López y Muñoz, 2011, p. 20).

La relación bilateral Chile-Perú es analizada desde la dimensión histórica/económica, sin abordar con profundidad las dinámicas políticas y las relaciones de poder que se expresarían en constructos discursivos que articulan las elites políticas y su reproducción en los medios de comunicación. En este contexto, estudios preliminares han concluido que "la imagen de ganador y vencido y su repercusión en el alma nacional se mantienen hasta hoy pero adquieren nuevas formas y se unen a nuevas imágenes que ayudan a construir una percepción fundamentalmente antagónica del otro" (Milet, 2004, p. 231; énfasis propio), y a pesar de los avances sustantivos en materia comercial, "no se haya logrado un mayor desarrollo en la solución de la agenda histórica, en la que se pueden identificar una serie de demandas insatisfechas por parte de los peruanos" (Milet, 2004, p. 228). Podemos constatar que existen premisas compartidas en la literatura sobre la relación Chile-Perú que exaltan el hecho de que la relación esté condicionada por la herencia histórica que se evidencia en la existencia de una serie de imágenes antagónicas. En efecto, la noción de dos países rivales, que evoca la construcción "amigo-enemigo" de Carl Schmitt, es aplicable desde la perspectiva del conflicto. Sin embargo, la reflexión sigue anclada en los hechos históricos del siglo XX como gran hito "Guerra del Pacífico", "ganadores", "perdedores" y la generación de discursos por parte de las elites políticodecisionales que alimentan la denominada "identidad nacional" que, en ambos países, adquiere dinámicas y variables culturales distintivas en las formas, pero similares en el resultado. 
En el caso de Chile destaca "el orgullo de la victoria", la cuestión concreta de reivindicar los territorios anexados y la posición histórica de exaltar a los "guerreros y soldados chilenos", validando desde una fijación parcial que los conflictos con los vecinos "Perú" y "Bolivia" responden a intereses de los otros. Se constituye un ejercicio de mirarse a sí mismo sin reconocer a un otro distinto.

En estudios de comunicación mediada intercultural desde la perspectiva del análisis crítico del discurso, se corrobora que, al comparar dos medios de comunicación escritos Chile-Perú en el año 2010, ambos utilizan como marco contextual de sus discursos y posiciones la "Guerra del Pacífico”. Para Browne y Yáñez (2012), este conflicto bélico ha tenido gran injerencia en las conformaciones identitarias nacionales de y entre ambos países, evidenciándose notoriamente las mutuas desconfianzas históricas. En una comparación de noticias en dos medios que responden a lógicas y públicos objetivos similares, El Mercurio de Chile y El Comercio de Perú, los autores concluyeron que El Mercurio

construye sus discursos sobre la polarización Nosotros/Ellos, adscribiéndose a un "nosotros los chilenos" en relación a un "ellos los peruanos" y apela a situaciones sociales, políticas, económicas e históricas para acentuar la superioridad de Chile, sus gobiernos y ciudadanos, por sobre Perú. (Browne y Yáñez, 2012, p. 191).

El diario El Comercio de Perú "apunta principalmente a situaciones socio-políticas e históricas en favor de la unidad nacional, destacando su proceder pacífico y correcto por sobre Chile”. (Browne y Yáñez 2012, p. 191; énfasis propio) y también se aprecia la polarización nosotros/ellos como una constante, llegando a identificarse explícitamente como medio nacionalista al referirse al diferendo marítimo que sostienen Chile y Perú: "El Comercio, fiel a su tradición de invariable defensor de los derechos de nuestro país, de aquellos asuntos que constituyen una política de Estado, un objetivo nacional, del cual nadie puede sentirse distante ni ajeno" (Browne y Yáñez, 2012, p. 191; énfasis propio).

Junto con lo expuesto, desde la perspectiva de los discursos políticos de las elites chilenas, un elemento discursivo relevante apela a la validación de un "otro Perú", desde la tesis de la validación económica, basados en el supuesto de que "el fortalecimiento de las relaciones económicas entre Estados reduce la probabilidad de conflicto (...) el comercio tiene elementos que pueden actuar como pacificadores o generadores de espacios de diálogo" (López y Muñoz, 2011, p. 16). De acuerdo con lo anterior, surge el matiz-sello que permite reconocer al "otro Perú" como un modelo de desarrollo económico con la 
matriz neoliberal que potencia las inversiones extranjeras y es un aliado en la relación con China.

Las lógicas del capitalismo global y la importancia de las relaciones económicoempresariales se instalan en el discurso público desde los años 90 como el elemento dinamizador de las relaciones bilaterales Chile-Perú, siendo interesante la negación de la existencia de conflictos políticos, argumentando que la clave del éxito de la relación comercial configura el todo de las relaciones chileno-peruanos. En este sentido, la variable de las migraciones de peruanos a Chile empieza a ser significativa (en el marco de las migraciones sur-sur) en el mismo período en que se asocia a la imagen de éxito de la economía chilena, junto con la estabilidad institucional, como los factores explicativos que se instalan como argumentos de intereses comunes con Perú.

\section{El diferendo marítimo Chile-Perú: las posiciones y discursos de los Estados}

En este trabajo interesa problematizar sobre los discursos y construcción de imaginarios sociales de las elites políticas y su reproducción en los medios de comunicación escritos, considerando el contexto del diferendo marítimo Chile-Perú en la Corte Internacional de Justicia. Específicamente, interesa analizar las ideas, nociones y dimensiones que conforman los discursos e imágenes ex post fallo. ${ }^{3}$

Para comprender las lógicas y ámbito de acción del conflicto, es necesario recordar que Chile y Perú son parte del Tratado Americano de Soluciones Pacíficas (Pacto de Bogotá), que establece que los Estados pueden presentar demandas a una instancia con jurisdicción internacional cuando los Estados, por la vía diplomática y negociaciones, no llegan a acuerdos.

La demanda de Perú ante la CIJ se realizó el 16 de enero del 2008 durante el gobierno del presidente Alan García (2006-2011) y el primer gobierno de Michelle Bachelet (20062010), quien debe responder a la primera fase de la demanda. Cabe señalar que en el caso de Perú es un trabajo de elaboración del texto y argumentación jurídico-política de más de dos décadas. En el caso de Chile las respuestas se basaron en negar la existencia de "temas no resueltos"; por tanto, Chile en sus argumentos siguió el guion conocido de mantener

3 Por tanto, el análisis de información tiene como eje temporal el 27 de enero de 2014 y el 30 de agosto de 2014. 
el statu quo, sustentando tal posición en la estabilidad del régimen internacional. En este sentido, podemos mencionar que el proceso de la demanda responde a diferentes fases basadas en las lógicas del derecho internacional.

La fase escrita (Memoria, Contramemoria, Dúplica) es reservada y la fase oral corresponde a la parte pública; el proceso del juicio dura más de seis años antes de que la Corte dicte sentencia. Es interesante destacar que la fase oral es durante la cual se visibilizan las posiciones y argumentos jurídicos, políticos, históricos, sociales y culturales de ambos países que son reproducidos por los medios de comunicación de masas con los componentes de espectacularidad, encapsulamiento y dramatización (Mouchon, 1998).

A continuación se presenta el Cuadro $\mathrm{N}^{\circ} 2$, que resume las posiciones de Chile y Perú en el contexto del diferendo marítimo.

Cuadro $\mathrm{N}^{\circ} 2$

Resumen de posiciones de Chile y Perú en el contexto del diferendo marítimo

\begin{tabular}{|c|c|c|}
\hline Fallo de la CIJ & Posición de Chile & Posición de Perú \\
\hline $\begin{array}{l}\text { Se reconoce hito } 1 \text { como punto de } \\
\text { referencia. } \\
\text { Los Acuerdo del } 52 \text { y } 54 \text { son reco- } \\
\text { nocidos como "Acuerdos tácitos" } \\
\text { de delimitación entre Chile y Perú. } \\
\text { Se respetó la línea marítima que } \\
\text { defendía Chile hasta las } 80 \text { millas } \\
\text { marinas solamente, estableciéndo- } \\
\text { se un nuevo trazado marítimo que } \\
\text { desde las } 80 \text { millas toma una direc- } \\
\text { ción suroeste a partir de las líneas } \\
\text { base de ambos países. Esta última } \\
\text { se extiende hasta las } 200 \text { millas. }\end{array}$ & $\begin{array}{l}\text { Hito } 1 \text { como punto de } \\
\text { referencia para delimi- } \\
\text { tar el curso línea límite. } \\
\text { Existencia de Tratados } \\
\text { de delimitación Ma- } \\
\text { rítima Declaración de } \\
\text { Santiago } 1952 \text { y } 54 \text { entre } \\
\text { Chile y Perú más Ecua- } \\
\text { dor, Acuerdos posterio- } \\
\text { res } 68 \text { y } 69 . \\
\text { La línea marítima se ex- } \\
\text { tiende hasta } 200 \text { millas } \\
\text { marítimas. }\end{array}$ & $\begin{array}{l}\text { Punto Concordia como } \\
\text { punto de referencia. } \\
\text { Inexistencia de Tratados } \\
\text { marítimos (los acuerdos } \\
\text { del } 52 \text { y } 54 \text { son solamente } \\
\text { acuerdos pesqueros. } \\
\text { Solicita derecho sobera- }\end{array}$ \\
\hline
\end{tabular}

Fuente: elaboración propia. 
En el contexto del fallo de La Haya, el dictamen es parte de un escenario tendencial sobre la base de otros juicios similares que se han desarrollado; por tanto, el desempeño de la CIJ y sus lógicas tienen componentes políticos, jurídicos y simbólicos. En este tópico, interesa observar la mirada global y eurocéntrica que se instala en la comunidad política y en la ciudadanía, adquiriendo relevancia central la percepción de que "los intereses del Estado-nación están en juego" en un territorio que representa la administración de justicia e imparcialidad que encarna los principios del derecho internacional, sin mencionar el mercado que se genera en la oferta de "abogados" que representan a países que entregan el mandato a un tercer actor para que en la arena jurídica resuelvan conflictos políticos/ históricos (la industria del derecho internacional).

Asimismo, en este escenario la sentencia de la CIJ genera debates, interpretaciones y discusiones sobre el desempeño de la política exterior de los países y sus ejes de acción, conformándose las etiquetaciones del problema público (Nelson, 2001) y la fijación parcial de los conceptos sobre justicia. En este punto surgen preguntas en la agenda de los medios de comunicación, tales como ¿el fallo responde a criterios jurídicos estrictos ajustados al derecho internacional o se basa en principios de justicia distributiva?

\section{Los discursos en los medios de comunicación: la autopresentación y la otra presentación ex post fallo de La Haya}

La trayectoria de los eventos y discursos que son parte del escenario político de Chile y Perú durante los meses de enero-agosto 2014, revisten especial relevancia para comprender las dinámicas políticas nacionales, la configuración de un discurso que exalta el nacionalismo, y el uso de conceptos como "soberanía", "territorio", "defensa" e "intereses nacionales". En este contexto se pueden identificar las ideas centrales de los discursos del presidente de Chile, Sebastián Piñera, una semana antes del fallo de la CIJ, en particular en el mes de enero del año 2014, al convocar al Consejo de Seguridad Nacional (Cosena) y realizar declaraciones tales como: "Las fuerzas armadas están preparadas para defender soberanía y mar. Chile es amante de la paz y respetuoso del derecho, pero tiene unas Fuerzas Armadas preparadas para defender su soberanía”. (La Tercera, 9 de noviembre, 2014). 


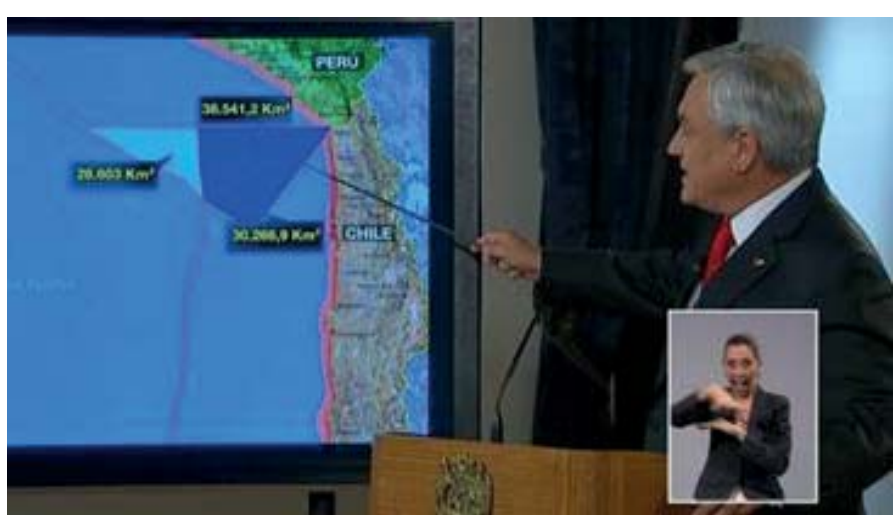

Imagen $\mathrm{N}^{\circ} 1$ : Discurso del presidente de Chile Sebastián Piñera ex post fallo, 27 de enero de 2014. Fuente: www.tvn.cl

El presidente Piñera realiza un discurso en cadena nacional, desde el Palacio de La Moneda, dirigiéndose al país con un estilo solemne, identificándose un sello distinto a otros mensajes: la utilización de un mapa y un puntero apelan al saber didáctico para explicar el resultado del fallo, realizando las siguientes declaraciones:

Se ratifica el dominio chileno del triángulo terrestre respectivo (...) los puntos esenciales de Chile fueron considerados en el fallo". Se exalta el reconocimiento de acuerdos limítrofes entre ambos países y lamenta que se consideraba que faltaba claridad de los acuerdos para explicar la línea equidistante. "Este presidente y la presidenta electa asegurarán todas la medidas y acciones para resguardar los legítimos derechos e intereses de Chile. (24 horas TVN, enero 2014).

a. Las ideas fuerza que son reproducidas en los discursos públicos por parte del presidente de Chile Sebastián Piñera, el día del fallo de La Haya (27 de enero, 2014), son las siguientes:

"Hoy la Corte ha confirmado en lo sustancial la posición chilena (...) Chile mantiene casi la totalidad de sus derechos de pesca." (La Tercera, 28 de enero, 2014); "Chile cumplirá y exigirá el cumplimiento del fallo, pero dada la naturaleza de éste, la implementación deberá ser gradual." (El Mercurio, 28 de enero, 2014). Apela a la unidad de chilenos y chilenas exaltando la defensa de los intereses del Estado 
b. Ideas fuerza del discurso de la Presidenta electa (marzo 2014-2018), Michelle Bachelet, ex post fallo:

El Fallo constituye una pérdida dolorosa (...) sin embargo se ha reconocido la existencia de un acuerdo en el hito 1 y el paralelo limítrofe, o sea, que no hay traspaso alguno de soberanía territorial de Chile. (...) Trabajaré para que la sentencia se aplique de manera gradual y velando por los legítimos intereses de Chile. Agregó que "esperamos que Perú adopte este fallo para tomar las medidas y normas adecuadas para ejecutar la sentencia. Éste es el momento de tener unidad como país. Chile ha defendido sus derechos de manera legítima en el marco del derecho internacional. (La Segunda, 27 de enero, 2014).

En ambos discursos se mantienen las denominadas "fuerzas profundas" de la política exterior chilena, que apelan a la estabilidad en relación con la soberanía territorial y la unidad nacional en una lógica de arriba hacia abajo. Cabe señalar que el discurso de Bachelet incorpora el factor emotividad al señalar "pérdida dolorosa" y refuerza el mensaje de "mantención de las fronteras" utilizando el mitigador "sin embargo se ha reconocido la existencia de un acuerdo en el hito 1 ".

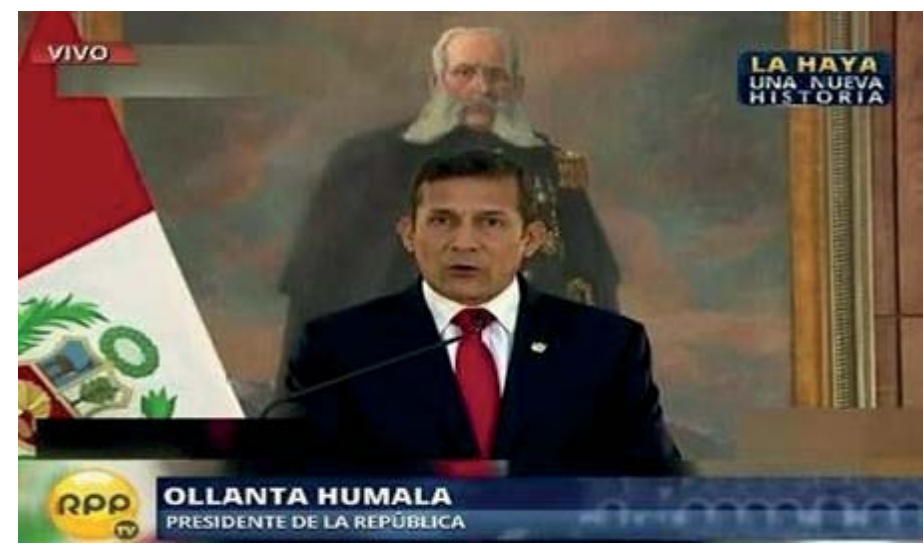

Imagen $\mathrm{N}^{\circ}$ 2: Discurso del presidente de Perú Ollanta Humala ex post fallo el 27 de enero de 2014. Fuente: www.rpp.com.pe

En el discurso del Presidente Humala se aprecia el estilo solemne desde el Palacio de Gobierno peruano -también conocido como la Casa de Gobierno o la Casa de Pizarro-, con el uso de las banderas respectivas y el protocolo. Es muy significativo que en la puesta en escena del discurso esté la imagen de Andrés Cáceres, ícono del movimiento nacionalista 
peruano denominado "etnocacerismo"; por tanto, se constituye una dimensión simbólica que apela a la historia y a reivindicaciones político-históricas.

Las frases del discurso apelan al triunfo y se exalta que la posición peruana, a juicio del Presidente Humala, "logra más del 70\% de la demanda". Al analizar el uso del léxico en contexto, es significativo el uso de la cifra con fines persuasivos para exaltar el mensaje de triunfo y cumplimiento de los resultados. En este sentido, se utiliza el meta colectivo plural "pueblo" para conectar los logros de la demanda con la dimensión emotiva que reivindica los anhelos históricos, el uso de la exageración con fines retóricos y el uso de afirmaciones que encapsulan los mensajes connotativos de la posición de Perú.

Las principales ideas fuerza del discurso del Presidente de Perú Ollanta Humala son las siguientes: "Es motivo de satisfacción que la Corte haya admitido parte de la demanda."; "Perú se siente complacido de esta nueva opción de paz."; "El Perú puede sentirse satisfecho de la labor cumplida"; "Involucra orgullo nacional"; "Es parte del esfuerzo del pueblo peruano." ; "Esto es un triunfo para la paz y una satisfacción para el pueblo" (El Comercio, 27 de enero, 2014).

Aprovechando la oportunidad política, el presidente de Bolivia Evo Morales manifestó que "se siente alentado por fallo sobre Chile y Perú" y anuncia que la memoria de Bolivia está lista y va a avanzar en la CIJ para demandar la obligación de negociar un acceso soberano al mar. En tanto, el presidente de Ecuador Rafael Correa, que había sido clave durante el juicio al no hacerse parte y definir acuerdos con Perú sobre temas marítimos, se vincula al caso felicitando a Chile y Perú. Ambos hechos son indicativos que las reacciones ex post fallo de La Haya tienen implicancias en las interacciones políticas de la región latinoamericana y son variables interdependientes que requieren ser consideradas en el análisis político ${ }^{4}$.

A continuación se presenta un mapa ramificado de los titulares "Fallo de La Haya / Diferendo marítimo Chile-Perú”

$4 \quad$ En el diferendo marítimo Chile-Perú, Bolivia solicitó copia de la memoria, contramemoria, réplica y dúplica. En la demanda de Bolivia hacia Chile por el acceso al mar, la cancillería peruana ha solicitado una copia de la memoria. 


\section{Cuadro $\mathrm{N}^{\circ} 3$}

Mapa ramificado de titulares de prensa Fallo de La Haya / Diferendo marítimo

Chile-Perú

\begin{tabular}{|c|c|c|c|c|c|c|c|c|c|c|c|c|c|}
\hline \multirow{5}{*}{ Bachelet } & \multirow{2}{*}{ Chile } & \multirow{3}{*}{ Aprobación } & Mut̃oz & Canciller & Más & Burgos & Dejar & Evitar & Heraldo & Nuevas & Reúne & Acuerda & Ahora \\
\hline & & & \multirow{4}{*}{ Partidos } & Coules. & Perpun & Comité & Desde & Fallo & Humala & Nuevos & Semana & Alfredo & Participe \\
\hline & \multirow{4}{*}{ Perú } & & & & & & & & & Peor $>$ & Tarud & Alicia & Argentina \\
\hline & & \multirow{4}{*}{ Gabinete } & & \multirow{3}{*}{ Cita } & \multirow{3}{*}{ Años } & Confirms & Embajada & Final & Larrain & & Tersentra & & \\
\hline & & & & & & & & & & Politicos & & & \\
\hline \multirow{9}{*}{ Piñera } & & & & & & & & & Mar & & \begin{tabular}{|l} 
Principal \\
\end{tabular} & Protesta & Anotan \\
\hline & \multirow{8}{*}{ Adimark } & & & 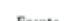 & Arime & & & & Medides & I.to & Tiene & Triangulo & Ahora \\
\hline & & Gobiemos & \multirow{7}{*}{ Alianza } & \multirow{7}{*}{ Habla } & \multirow{7}{*}{ Insiste } & \multirow{4}{*}{ Cuestiona } & \multirow{4}{*}{ Entre } & \multirow{4}{*}{ Habria } & \multirow{5}{*}{ Medio } & & 2008 & Administra & Aprobó \\
\hline & & \multirow{6}{*}{ Ministros } & & & & & & & & & 2014 & Andina & Arribo \\
\hline & & & & & & & & & & Primer & 350 & Anuncia & Atribuye \\
\hline & & & & & & & & & & & Actuales & Anuncio & Autoridad \\
\hline & & & & & & \multirow{3}{*}{ Cumbre } & \multirow{3}{*}{ Envio } & \multirow{3}{*}{ Hace } & & \multirow{3}{*}{ Rechazo } & Promueve & Aporta & Avances \\
\hline & & & & & & & & & \multirow{2}{*}{ Mcjor } & & Traspaso & Proyecto & Arrendo \\
\hline & & & & & & & & & & & Alcalde & $\mathrm{Vez}$ & Anticipo \\
\hline
\end{tabular}

Fuente: elaboración propia.

Anotemos ahora una generalidad importante. Como puede apreciarse en el mapa ramificado correspondiente, las palabras "Bachelet" y "Piñera" tienen una presencia importante en los titulares de los medios de comunicación escrita registrados y sistematizados en el período 27 de enero de 2014 a 31 de agosto de 2014. También aparecen destacadas las palabras "Chile", "Perú" y "Adimark". Se observa la importancia de las figuras del Presidente de Chile saliente "Piñera" y la presidenta que asume el gobierno el 11 de marzo de 2014, "Bachelet", ${ }^{5}$ y de nombrar a los dos países como protagonistas del diferendo marítimo. Un elemento interesante es la relevancia que adquiere la palabra "Adimark", que corresponde al nombre de la empresa que realiza encuestas de opinión y evaluaciones de las figuras públicas. Específicamente, la empresa entrega un ranking de aprobación de los presidentes, ministros y personeros públicos. Este elemento indicaría que la "aprobación" sobre la gestión de los presidentes y la percepción de la ciudadanía es un tema estratégico, y con mayor frecuencia en la selección de los temas por parte de los medios de comunicación escrita chilenos.

5 Cabe señalar que la presidencia de Michelle Bachelet comienza su segundo período presidencial el 11 de marzo del año 2014 y finaliza el 11 de marzo del año 2018; representa a la coalición de centro izquierda Nueva Mayoría. Además, en el cambio de gobierno se aprecia la salida de la administración del Presidente Piñera (2010-2014), que representaba a la coalición de centro derecha: Alianza. 
Por su parte, "gobierno", "gabinete" y "ministros" refuerza una mirada singular centrada en los aspectos de política nacional, construyendo el relato sobre el tópico "Diferendo Marítimo en La Haya" con una lógica endógena. Es interesante que los ministros mencionados sean "Muñoz, Heraldo" y "Burgos", el primero ministro de Relaciones Exteriores de Chile y el segundo ministro de Defensa Nacional. Ello vincula la relación política con la noción de seguridad y defensa, sugiriendo una manera particular de entender la política internacional asociada a la trilogía Estado-nación-territorio.

En el análisis de los discursos y su reproducción en los medios de comunicación, resulta destacable observar las encuestas publicadas durante el mes de enero de 2014 sobre los juicios y evaluaciones de los chilenos y peruanos acerca de las expectativas y resultados del fallo de La Haya. Se observa que en las encuestas publicadas por dos medios de comunicación: en el caso de Chile la encuesta publicada por el diario La Segunda-UDD afirmaba que "el $82 \%$ de los chilenos piensa que será favorable para Chile el fallo de La Haya" y con respecto a la pregunta si se resuelven los conflictos con Perú una cifra del $69 \%$ cree que Perú seguirá "creando nuevas reclamaciones contra Chile".

\section{El caso Chile-Bolivia}

La relación bilateral entre Chile y Bolivia ha estado marcada por la desconfianza y la ausencia de relaciones diplomáticas formales en las últimas décadas, pudiendo sugerir que responde a las características de un "conflicto político institucionalizado", aquel en que los actores hacen explícitas sus posiciones divergentes en torno a un evento o situación específica de forma sistemática, que se repite en ciertos intervalos temporales, tornándose habitual la tensión, pero sin desbordar los límites institucionales. Es decir, la conflictividad es estructurada por prácticas, discursos e ideas que se anclan en instituciones (Quiroga, Guerrero y Schuster, 2016). En este caso, a diferencia de la relación con Perú, se ha mantenido una relación lejana, distante, sin mediar la dimensión económica como argumento que materializaría la integración. Para varios autores es reconocible que la relación con Bolivia ha tenido una "dimensión geopolítica, económica y militar que ha sido más lenta en comparación con Perú" (Deustua, 2004, p. 11) y el intercambio comercial chileno-boliviano es bajo en comparación con las inversiones que han realizado las empresas chilenas en Perú y el resto de la región.

Colacrai y Lorenzini (2005) observan la presencia de elementos identitarios en la política exterior chilena y su relación con los países vecinos, identificando las "fuerzas 
profundas" y las tendencias de la política exterior. Las autoras logran detectar, entre otras, la estabilidad institucional, la importancia del factor territorial durante la conformación temprana del Estado-nacional, la búsqueda de equilibrio geopolítico regional y el estilo civil-pragmático de la diplomacia como factores determinantes de la proyección internacional. En particular, el factor territorial en la relación Chile-Bolivia "ha obstaculizado el establecimiento de relaciones maduras (...) ambos países han roto relaciones diplomáticas. Resultando ser una de las relaciones más conflictivas de la región" (Colacrai y Lorenzini, 2005, p. 53).

En el análisis del caso, la demanda de Bolivia se formaliza en abril de 2014 y se basa en la teoría de los actos unilaterales y los derechos expectanticos. La memoria recopila en detalle todos los "actos unilaterales" que Bolivia considera incumplimientos de Chile en su obligación de negociar una salida al mar: conversaciones en la administración de González Videla el año 1956; negociaciones entre los dictadores Banzer de Bolivia y Pinochet de Chile en 1976; agenda de los 13 puntos del primer gobierno de Bachelet en el año 2008, entre otros hitos relevantes que son sistematizados y parte de la fundamentación de la demanda boliviana en el marco de apelar a los "actos unilaterales".

La respuesta de Chile en este caso ha sido impugnar la competencia de La Haya y establecer una agenda comunicacional para promocionar la posición de Chile, elaborando un folleto primero y un video luego, ambos intitulados: "La aspiración marítima boliviana: mito y realidad"6. El texto audiovisual tiene como protagonistas a la Presidenta Michelle Bachelet y al propio canciller Muñoz, junto a los ex presidentes Eduardo Frei, Ricardo Lagos y Sebastián Piñera, quienes explican las principales razones de por qué Chile pidió la incompetencia de la Corte Internacional ante la demanda de Bolivia.

a. Ideas fuerza de la posición de Chile frente a la demanda de Bolivia en La Haya

Chile le ha otorgado una serie de beneficios a Bolivia que le otorgan un acceso al mar por los puertos de Arica y Antofagasta.

Chile y Bolivia tienen límites claros fundados en el vigente Tratado de 1904.

La demanda de Bolivia en la CIJ pone en juego el desarrollo normal de las relaciones internacionales y el respeto por los límites establecidos

$6 \quad$ El 15 de julio de 2016 se difundió una nueva pieza audiovisual obre la Contramemoria presentada por Chile ante la Corte Internacional de Justicia de La Haya, por la demanda marítima boliviana. 
Bolivia pretende lograr, mediante una demanda artificial e inédita, la revisión del Tratado de Paz y Amistad de 1904 (...) El gobierno de La Paz busca modificar lo que está regulado por ese tratado, es decir, los límites entre nuestros dos países", dijo ayer Muñoz.

En esto hemos compartido posiciones todos, sin excepción, sin ideologías, porque aquí lo que está en juego son los intereses de nuestro país. (La Tercera, 2 de octubre, 2014).

\section{b. Ideas fuerza respuesta de Bolivia frente a la impugnación de la demanda realizada por Chile y la promoción de un video que difunde la posición de Chile}

Chile usurpó $120.000 \mathrm{~km}^{2}$ de territorio y $400 \mathrm{~km}$ lineales de costa con los que Bolivia había nacido como República en 1825.

Existen violaciones flagrantes por parte de Chile al Tratado a lo largo de la historia.

Hay autonomía aduanera limitada de Bolivia en los puertos de Arica y Antofagasta.

El Ferrocarril Arica-La Paz se encuentra suspendido desde 1997 para pasajeros y desde 2001 para el transporte de carga debido a problemas en una sección chilena.

Chile le hizo a Bolivia, después del Tratado, siete ofertas concretas de devolverle soberanía sobre el océano Pacífico.

La mayor riqueza económica de Chile, el cobre, está situada exactamente en el desierto de Atacama, que hasta 1879 era propiedad de Bolivia. (La Razón, 10 de julio, 2014).

De acuerdo con las ideas fuerza identificadas, en el caso de Chile, el guion público reitera los ejes argumentativos apelando a la inviolabilidad de los tratados internacionales, la seguridad e integridad de las fronteras y el estricto apego al derecho internacional. Sin embargo, se adopta la decisión de invalidar la demanda objetando la competencia del tribunal y se genera un discurso consistente con ese paso táctico que intenta demostrar que Chile ha cumplido el Tratado de 1904 y que Bolivia tiene acceso al mar por los puertos chilenos del norte, exaltando el uso de las cifras que intentan demostrar que Bolivia tiene beneficios y recibe colaboración de Chile para que pueda "acceder al mar para trasladar 
sus productos". En este contexto, Chile ha planteado en reiteradas oportunidades que no cederá soberanía; la posición es clara, enfática y es parte de un guion que reproduce la elite política y que tiene alta legitimidad emotiva en la población. La base de la defensa chilena en cuanto a la incompetencia de la Corte es demostrar que Bolivia pretende modificar, mediante el juicio, un tratado vigente entre ambos países.

La estrategia comunicacional de Chile expresa el modo de ejercicio del poder político basado en los acuerdos transversales de la elite partidaria bajo la lógica del carácter trascendente de la política exterior. La siguiente foto refleja una reunión de la Presidenta Bachelet realizada el 23 de mayo de 2014, a la cual se convocó a todos los presidentes de partidos políticos, con representación parlamentaria, para discutir sobre la demanda de Bolivia en La Haya.

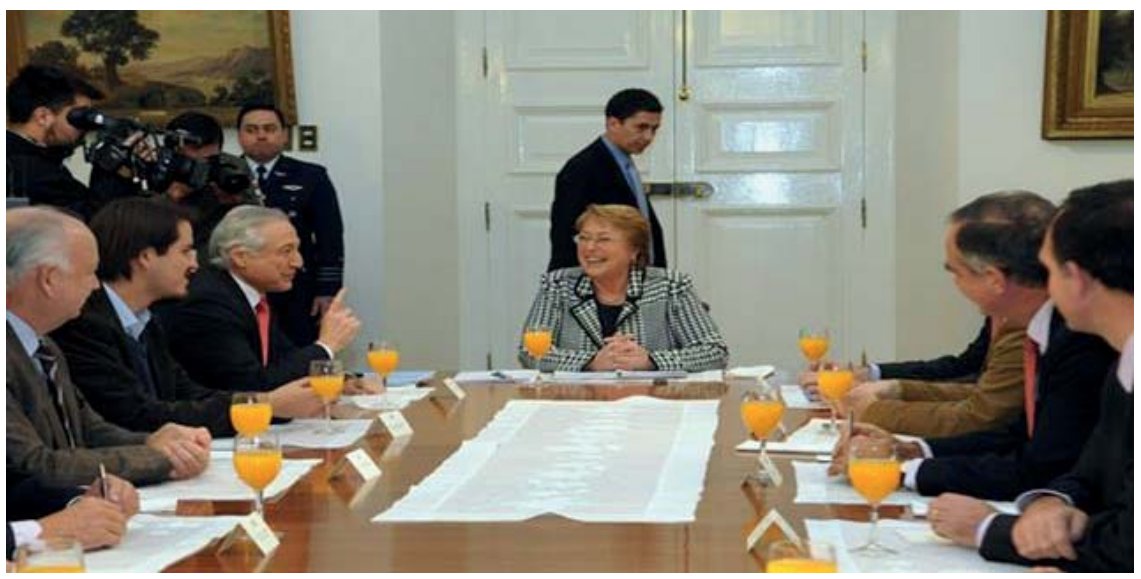

Imagen $\mathrm{N}^{\circ}$ 3: Presidenta Bachelet reunida con los presidentes de partidos políticos por demanda de Bolivia en La Haya. Fuente: La Segunda, 23 de mayo, 2014.

En la imagen se representa la "política de Estado", siendo altamente significativa la inexistencia de perspectivas críticas en el discurso de la centro-izquierda y la centroderecha sobre el tópico "demanda de Bolivia en La Haya”. Se puede constatar que todos los partidos políticos emiten declaraciones públicas respaldando la posición del Estado de Chile, enfatizando que no hay temas pendientes y relevando la necesidad de resguardar los intereses nacionales y la soberanía. Adscritos a ese marco consensual, el Partido Progresista (PRO) y el Partido Comunista (PC) declaran la necesidad de "profundizar lazos con Bolivia". En el caso de los partidos de centro-derecha, expresan que "hemos 
tenido diferencias con el gobierno, pero en este tema tenemos coincidencia total (...) apoyamos totalmente cómo el gobierno está conduciendo el conflicto con Bolivia" (La Segunda, 23 de mayo, 2014) Por lo tanto, reforzando la idea del presidente del Partido Socialista, "no hay temas pendientes con Bolivia". quede este modo, los discursos políticos se estandarizan y las variables ideológicas se difuminan al apelar a la noción de Estadonacional y la política de unidad nacional. El nacionalismo, una vez más, demuestra su fuerza emocional, sus efectos políticos y, sobre todo, sus intereses ideológicos y lógicas de inclusión/exclusión, tanto fácticas (la elite política como equivalente a la "nación") como conceptuales (la fijación de conceptos que, en efecto, son polémicos).

Las encuestas sobre la demanda de Bolivia en La Haya publicadas en el mes de abril de 2014 por el diario El Mercurio planteaban que el 76,2\% de los chilenos consideraba que "la demanda marítima boliviana ante la CIJ no tiene fundamentos jurídicos sólidos", según el estudio Research realizado para el periódico mencionado. Esto empieza a constatar la posición de las elites políticas chilenas y sus logros en instalar la idea de que la demanda boliviana no se ajusta al derecho internacional y, en este caso, la negación y exclusión del "otro Bolivia" empieza a ser constante en los discursos e ideas dominantes instalados en la agenda de los medios de comunicación. La comunidad imaginada nacional se refuerza en los discursos públicos mediatizados y encuentra una fuente de legitimidad políticoemocional en la población que se expresaría en tanto opinión pública.

\begin{tabular}{|c|c|c|c|c|c|c|c|c|c|c|c|c|c|}
\hline \multirow{5}{*}{ Bolivia } & \multirow{6}{*}{ Demanda } & \multirow{3}{*}{ Canciller } & \multirow{2}{*}{ Mun๊̂ช } & Chileno & Chilena & Pacto & Comisión & theremperente & Alista & Blanco & Obama & Como & Autoridad \\
\hline & & & & \multirow{2}{*}{ Contra } & \multirow{2}{*}{ Memoria } & Fallo & Compettaicia & Nómina & Correo & Corte & Abogado & Dice & Contra \\
\hline & & & \multirow{3}{*}{ Boliviana } & & & \multirow{3}{*}{ Gobiemo } & \multirow{3}{*}{ Confirmó } & \multirow{3}{*}{ Piñera } & \multirow{3}{*}{ Juicio } & \multirow{2}{*}{ Milenko } & Abordo & Perú & Critica \\
\hline & & \multirow{4}{*}{ Bachelet } & & \multirow{3}{*}{ Mar } & \multirow{3}{*}{ Pacto } & & & & & & \multirow{2}{*}{ Acceso } & \multirow{2}{*}{ Viaje } & \multirow{2}{*}{ Cuando } \\
\hline & & & & & & & & & & Preocupa & & & \\
\hline \multirow{9}{*}{ Halla } & & & \multirow{2}{*}{ Morales } & & & \multirow{2}{*}{ Moneda } & \multirow{2}{*}{ Dülogo } & \multirow{2}{*}{ Politica } & Lero & \multirow{2}{*}{ Primer } & Adviente & Agenda & Abogar \\
\hline & \multirow{8}{*}{ Chile } & & & Bogoti & Presidente & & & & Hama & & Cita & Ascsor & Analizar \\
\hline & & & & & & & & & & Rafael & Pais & Cinco & Causales \\
\hline & & & & & & Asesor & Entregar & Preparar & & & Tems & Comán & Criticas \\
\hline & & & & & & & & & Meritime & Carles & Afirma & Cónsul & Milenko \\
\hline & & Canciuter & Agente & Bulnes & Enfrentar & & & & & & Ante & Felipe & Cuentos \\
\hline & & & & & & neillent & Juouener & Teritevio & & Dethe & Antes & Postura & Condecir \\
\hline & & & & & & Cracilieties & Impugar & Ientionto & Mess & Deoce & Apoyo & Aboga & Agendar \\
\hline & & & & & & & & & mesa & & Artificial & Alentar & Abordable \\
\hline
\end{tabular}

Cuadro $\mathrm{N}^{\circ} 4$

Mapa ramificado de titulares de prensa de la demanda de Bolivia en La Haya

Fuente: elaboración propia. 
Al analizar los mapas ramificados se constata, al igual que en el caso Chile-Perú, la importancia que le otorgan los medios de comunicación a los actores institucionales validados para hablar en representación de los Estados. Particularmente en Chile, destaca la figura presidencial y el canciller Muñoz. La imagen de totalidad y unidad que expresan las nociones "Chile" y "Bolivia", además de las vocerías oficiales, ratifican la exclusión pública de otros actores y de perspectivas alternativas. Asimismo, es sugerente gráficamente la mediación que la Corte Internacional de Justicia ("Haya") realiza de los Estados "Chile" y "Bolivia", ratificando el rol central de un actor europeo en una disputa de dos actores vecinos periféricos.

El resto del mapa de conceptos confirma la relevancia que en los discursos mediáticos adquieren los actores institucionales y la terminología procesal del derecho. Finalmente, la aparición de "Perú" y "Correa" reflejan el efecto bola de nieve del caso, poniendo dudas sobre la efectividad de la estrategia de encapsulamiento de la diplomacia chilena.

\section{Conclusiones}

Al analizar los discursos públicos de actores políticos-institucionales en los casos ChilePerú y Chile-Bolivia, se evidencian argumentos los estandarizados “interés nacional” y "resguardar nuestras fronteras", apelando al imaginario colectivo de "nuestra identidad chilena" (el tema del nacionalismo) y lo que "perdemos en el fallo", en relación con un otro lejano y distante que es "Perú", validado y escuchado desde el escenario del demandante/demandado. Tal lógica jurídica genera las condiciones materiales para el encuentro/desencuentro, pero sin problematizar sobre las lógicas de los Estados en un sistema interconectado con capitales trasnacionales y ciudadanos que son interpelados en las coyunturas cargadas de incertidumbres.

Por ejemplo, la noción de "soberanía" es un concepto polisémico, que es, sin embargo, fijado en uno de sus significados posibles. En este sentido, los límites parecen ser más bien conceptuales y epistemológicos, y el refuerzo de la importancia de los límites fronterizos resultaría, en cambio, una estrategia interesada por parte de los actores políticos participantes del conflicto. Ciertamente no se puede desconocer ni desatender la legitimidad y fuerza emocional que la comunidad imaginada nacional posee en las poblaciones nacionales, aunque parece necesario observar la matriz de los discursos de actores político-institucionales predominantes en la esfera pública mediatizados por 
los medios de comunicación para evaluar su efecto en la conformación de la "opinión pública”.

La historia político-cultural de la relación Chile-Perú y Bolivia demuestra la fuerza del nacionalismo como un principio de unidad política y nacional que, por tanto, configura relaciones del tipo nosotros/ellos.

Lo interesante es constatar que, en menos de un año, Chile ha sido demandado por dos países vecinos y que el tema de fondo que se soslaya en los debates públicos es la capacidad de negociación de la diplomacia para manejar las relaciones vecinales con Perú y Bolivia: parece relevante ponderar la supeditación de la política a lo jurídico y la sobrevaloración de la mirada económico-comercial en la política exterior.

Los discursos públicos siguen anclados a los hechos históricos del siglo XX, siendo el gran hito la "Guerra del Pacífico", "ganadores", "perdedores", y la generación de discursos por parte de las élites político-decisionales que alimentan la denominada "identidad nacional" y que, en los tres países, adquieren dinámicas y variables culturales distintivas en las formas, pero similares en el resultado.

En el caso de Chile se destaca "el orgullo de la victoria", la cuestión concreta de reivindicar los territorios anexados y la posición histórica de exaltar a los "guerreros y soldados chilenos", validando desde una fijación parcial el hecho de que los conflictos con los vecinos "Perú" y "Bolivia" responden a intereses de los otros. Se constituye así un ejercicio de mirarse a sí mismo sin reconocer a un otro distinto y desde una "aparente superioridad" se apela a que el derecho está con Chile.

La base de la defensa chilena es apelar a que el derecho está de su parte y desde que se inicia la demanda de Bolivia se ha mencionado la incompetencia de la Corte, advirtiéndose los "peligros" que implica esta demanda al pretender modificar, mediante el juicio, un tratado vigente entre ambos países. Cabe señalar que el 24 de septiembre de 2015 se constituyó un hito relevante del proceso judicial, al rechazar la CIJ las objeciones preliminares presentadas por Chile; por consiguiente, se continuó con las fases establecidas en los procesos y se intensificaron las posiciones y discursos de los actores en una lógica de mayor uso de los antagonismos y las figuras retóricas. Sigue, así, el escenario de la demanda articulando el contexto de relaciones Chile-Bolivia, sin avanzar a un espacio de encuentro político-social desde las elites. 
Un aspecto llamativo en los dos conflictos es la generación de una industria del derecho internacional. La mirada eurocéntrica se instala en la comunidad política y la ciudadanía, adquiriendo relevancia central la percepción de que los intereses del Estado-nación están en "juego" en un territorio que representa la administración de justicia e imparcialidad, que encarna los principios del derecho internacional, sin mencionar el mercado que se genera en la oferta de "abogados" que representan a países que entregan el mandato a un tercer actor para que en la arena jurídica resuelvan conflictos políticos históricos.

Para finalizar, es relevante destacar la necesidad de repensar las relaciones vecinales de Chile, focalizándose en la dimensión político-estratégica con énfasis en una agenda de políticas de integración que supere los enfoques tradicionales. Resultaría necesario construir una mirada estratégica y de largo plazo de la política exterior en forma integral, constituyéndose una estructura de oportunidad para ambos países de redefinir las relaciones bilaterales, pasando de las "lógicas de frontera" a las lógicas de "zonas de integración”. Asimismo, potenciar los procesos de integración regional y liderazgos políticos con un enfoque integral, superando los enfoques restrictivos que apelan a una noción de soberanía y nación anclada al siglo XX.

\section{Referencias}

Anderson, B. (1993). Comunidades imaginadas. Sobre los orígenes y difusión del nacionalismo. México, México DF: Fondo de Cultura Económica.

Austin, J. (1955). How to Do Things with Words, Second Edition. Massachusetts, Estados Unidos: Harvard University Press.

Bauman, Z. (2006). La globalización. Consecuencias humanas. Buenos Aires, Argentina: Fondo de Cultura Económica.

Browne, R. y Yáñez, C. (2012). Comunicación intercultural mediada: construcción de realidad a través de un análisis crítico y complejo de los discursos periodísticos Chile y Perú. Alpha, 34, 173-196.

Castells, M. (1999). Globalización, identidad y Estado en América Latina. Santiago, Chile: PNUD. 
Colacrai, M. y Lorenzini, M. E. (2005). La política exterior de Chile. ¿Excepcionalidad o continuidad?: una lectura combinada de las fuerzas profundas y tendencias. Revista CONfines agosto-diciembre, 45-63.

Deustua, A. (2004). Perú, Bolivia y Chile: por una relación trilateral. Revista Chilena de Ciencia Política XXIV (2), 212-227.

Dirección General de Relaciones Económicas Internacionales (2012). La inversión directa de capitales chilenos en el mundo, 1990-diciembre. Santiago, Chile: Ministerio de Relaciones Exteriores de Chile.

Eagleton, T. (1997). Ideología. Una introducción. Barcelona, España: Paidós.

El Comercio. (2014, 27 de enero). Humala sobre La Haya: "Fue un triunfo de la razón jurídica”. Recuperado de http://elcomercio.pe/politica/gobierno/humala-sobre-hayafue-triunfo-razon-juridica-noticia-1787482

El Mercurio. (2014, 27 de enero). Chile en la Haya. Recuperado de http://impresa. elmercurio.com/Pages/NewsDetail.aspx? $\mathrm{dt}=2014-01-28 \& \mathrm{dtB}=13-08-2014$ 0:00:00\&PaginaId $=11 \&$ bodyid $=3$

El Mostrador. (2014, 11 de agosto). Jorge Burgos: Los chilenos siempre seremos inflexibles en defender la soberanía. Recuperado en http://www.elmostrador.cl/pais/2014/08/11/ jorge-burgos-los-chilenos-siempre-seremos-inflexibles-en-defender-la-soberania/

Galdames, L. (2010). El discurso del Estado a través de la creación del puerto libre de Arica. Aproximación semiológica. En A. Díaz Araya, A. Díaz Aguad y E. Pizarro Pizarro, (comps.), Arica Siglo XX. Historia y sociedad en el extremo norte de Chile (pp.13-21). Arica, Chile: Ediciones Universidad de Tarapacá.

González, S. (2010). Nación, salitre y frontera: siete momentos clave del proceso de integración de Tarapacá a Chile, 1880-1929. En G. Cid y A. San Francisco (eds.), Nacionalismos e identidad nacional en Chile. Siglo XX (pp. 63-106). Santiago, Chile: Editorial Bicentenario.

Hillgruber, C. (2009). Soberanía. La defensa de un concepto jurídico. Revista para el Análisis del Derecho. INDRET 1. Disponible en http://ssrn.com/abstract=1368364.

Hobsbawm, E. (1991). Nación y nacionalismo desde 1780. Barcelona: Crítica Grijalbo Mondadori. 
International Court of Justice (2014, 27 de enero). Maritime Dispute (Peru v. Chile). The Court determines the course of the single maritime boundary between Peru and Chile. No. 2014/2. Recuperado de http://www.icj-cij.org/docket/files/137/17928.pdf.

La Nación. (2014, 27 de enero). Chile lamentó la decisión de La Haya sobre la disputa territorial con Perú. Recuperado de http://www.lanacion.com.ar/1658969-chile-lamento-ladecision-de-la-haya-sobre-la-disputa-territorial-con-peru

La Tercera. (2014, 9 de noviembre). Piñera: "Chile tiene FF.AA. preparadas para defender nuestra soberanía, nuestro territorio y nuestro mar". Recuperado de http://www. latercera.com/noticia/politica/2011/11/674-404156-9-pinera-chile-tiene-ffaapreparadas-para-defender-nuestra-soberania-nuestro.shtml

- (2014, 28 de enero). La Haya respalda tesis de Chile, pero reduce su zona económica. Recuperado de http://www.latercera.com/noticia/politica/2014/01/674-562868-9-lahaya-respalda-tesis-de-chile-pero-reduce-su-zona-economica.shtml

. (2014, 2 de octubre). Canciller enfatiza que demanda de Bolivia ante La Haya "es artificial e infundada". Recuperado de http://www.latercera.com/noticia/ politica/2014/10/674-598383-9-canciller-enfatiza-que-demanda-de-bolivia-ante-lahaya-es-artificial-e-infundada.shtml

La Razón. (2014, 10 de julio). Bolivia ve que Chile 'confunde y desnaturaliza' demanda marítima. Recuperado de http://www.la-razon.com/index.php?_url=/nacional/ demanda_mar\%C3\%ADtima/CIJ-Bolivia-Chile-confunde-desnaturalizamaritima_0_2085991447.html

La Segunda. (2014, 27 de enero). Bachelet: "Fallo constituye una pérdida dolorosa". Recuperado de http://www.lasegunda.com/Noticias/Politica/2014/01/910073/Bachelet-Falloconstituye-una-perdida-dolorosa

(2014, 23 de mayo). Canciller Muñoz: "Hay una inclinación a impugnar la competencia de la corte de La Haya". Recuperado de http://www.lasegunda.com/ Noticias/Politica/2014/05/936886/Bachelet-se-reune-con-presidentes-de-partidospoliticos-para-analizar-demanda-boliviana

López, D. y Muñoz, F. (2011). Chile y Perú. La relación comercial y en inversiones. En J. García, F. Muñoz, D. López y R. Bueno (eds.), Documento 3 Generación Diálogo ChilePerú/Perú-Chile. Aspectos económicos y comerciales (pp. 13-39). Lima, Perú: Konrad 
Adenauer, Instituto de Estudios Internacionales, Pontifica Universidad Católica del Perú, Instituto de Estudios Internacionales, Universidad de Chile.

Martínez, J. (2005). Magnitud y dinámica de la inmigración en Chile, según el Censo 2002. Revista Papeles de Población 44, 109-147.

Milet, P. (2004). Chile-Perú: Las dos caras de un espejo. Revista de Ciencia Política XXIV (2), 220-235.

Mouchon, J. (1998). Mediatización de lo político. En G. Gauthier, A. Gosselin y J. Mouchon (comps.), Comunicación y Política, (pp. 9-28). Barcelona, España: Gedisa.

Nelson, B. (2001). Políticas públicas y administración: una visión general. En R. Goodin y H. Klingeman (eds.), Nuevo Manual de Ciencia Política, tomo II (pp. 795-860). Madrid, España: Istmo.

Oppenheim, L. (1961). Tratado de Derecho Internacional Público, tomo I. López Olivan, J. (trad.). Barcelona, España: Bosch.

Pardo, N. (2007). Cómo hacer análisis crítico del discurso. Una perspectiva latinoamericana. Santiago, Chile: Frasis.

Pelayo M. y Cabrera A. (2001). Lenguaje y Comunicación, aspectos teóricos generales, características, estructuras, naturaleza y funciones del lenguaje y la comunicación. Buenos Aires, Argentina: El Nacional.

Perú 21. (2014, 28 de enero). Se fortalecerá el intercambio comercial entre Perú y Chile. Recuperado en http://peru21.pe/opinion/se-fortalecera-intercambio-comercialentre-peru-y-chile-2167480

Pilleux, M. (2001) Competencia comunicativa y análisis del discurso. Estudios filológicos, 36, 143-152.

Quiroga, M. F. (2007). Manual de análisis de discurso y manejo de crisis comunicacionales. Santiago, Chile: Departamento de Gobierno, INAP, Universidad de Chile.

Quiroga, M. F., Guerrero, N. y Schuster, S. (2014). El caso del reajuste salarial en el sector público chileno (2010). Polis 38. Disponible en http://polis.revues.org/10232. DOI: $10.4000 /$ polis. 10232 
Rodríguez, J. (2014). Chile, Bolivia y la decisión de Bachelet. Santiago, Chile: Cono SUR. Recuperado de http://www.tendencias21.net/conosur/CHILE-BOLIVIA-Y-LADECISION-DE-BACHELET_a348.html

Sartori, G. (2000). La política. Lógica y método en las ciencias sociales. México D.F., México: Fondo de Cultura Económica.

Thompson, J. (2002). Ideología y cultura moderna. Teoría crítica social en la era de la comunicación de masas. México D.F., México: Universidad Autónoma de México.

Valdivieso, P. (2007). A propósito de las relaciones Chile-Bolivia-Perú: Percepciones, experiencias y propuestas. Revista de Historia de Chile y América 6 (2), 99-123.

Van Dijk, T. (1996). Análisis del discurso ideológico. Comunicación y Política, versión 6, 15-43.

- - - (2003). Dominación étnica y racismo discursivo en España y América Latina. Madrid: Gedisa.

- - - (2005a). Estructuras y funciones del discurso. México D.F., México: Siglo XXI Editores.

————. (2005b). Política, ideología y discurso. Quórum Académico 2 (2), 15-47.

Van Klaveren, A. (2011). Política internacional y derecho internacional. El análisis de los regímenes jurídicos internacionales. Anuario Argentino de Derecho Internacional AADI XX 201, 144-169.

Yin, R.K. (2009). Case study research. Design and methods. 4. ed. Thousand Oaks, California

Weber, M. (1979). El político y el científico. Madrid, España: Alianza.

White, J. (2013). Tomar en serio en lenguaje: Los fundamentos narrativos de la investigación en administración pública- México D.F., México: Fondo de Cultura Económica.

Wodak, R. y Meyer, M. (2003). Métodos de análisis crítico del discurso. Barcelona, España: Gedisa.

Woo, E. (2014, 27 de enero). Pescadores de Arica increpan a marinos tras fallo de La Haya. Santiago, Chile: Radio Biobío Chile. Recuperado en http://www.biobiochile. cl/2014/01/27/pescadores-de-arica-increpan-a-marinos-tras-fallo-de-la-haya.shtml 